\section{Contubernium Ochevi (Porifera, Hexactinellida)}

\section{Е. М. Первушов}

Первушов Евгений Михайлович, доктор геолого-минералогических наук, заведующий кафедрой, Саратовский национальный исследовательский государственный университет имени Н. Г. Чернышевского, pervushovem@mail.ru

Среди позднемеловых Ventriculitidae, париформный скелет которых наиболее просто построен, установлены представители семейства, характеризующиеся необычными новообразованиями. На парагастральной поверхности стенки этих губок (Contubernium), после ее отворота, регулярно расположены конусообразные субмодули, появление которых связывается с незавершенным почкованием. Парагастры субмодулей не сопряжены с центральной полостью губки, что позволило рассматривать Contubernium как перифронтальный организм, занимающий промежуточное положение между одиночными и модульными формами спонгий. Ареал этих раннесантонских губок локализован на территории правобережного Поволжья. Ключевые слова: губки, гексактинеллиды, перифронтальные формы, Contubernium ochevi, эндемики, поздний мел, сантон.

\section{Contubernium Ochevi (Porifera, Hexactinellida)}

\section{E. M. Pervushov}

Evgeny M. Pervushov, https://orcid.org/0000-0002-7962-0274, Saratov State University, 83 Astrakhanskaya St., Saratov 410012, Russia, pervushovem@mail.ru

Among the Late Cretaceous Ventriculitidae, with the most simply constructed pariform skeleton, representatives characterized by unusual neoplasms were identified. On the paragastric surface after the lapel of these sponges (Contubernium), cone-shaped submodules are regularly based, the appearance of which is associated with incomplete blastogenesis. Paragastra of submodules are not associated with the atrium, therefore, Contubernium is considered as a perifrontal organism, occupying an intermediate position between single and modular forms of spongia. The range of these Lower Santonian sponges is localized on the right-bank Volga territory.

Keywords: sponges, hexactinellids, perifrontal forms, Contubernium ochevi, endemics, Late Cretaceous, Santonian.

DOI: https://doi.org/10.18500/1819-7663-2019-19-4-267-278

Введение. При изучении относительно просто устроенных позднемеловых губок - гексактинеллид, представителей семейства Ventriculitidae $[1,2]$, установлены формы, в строении скелета которых выделены обособленные элементы, нехарактерные для вентрикулитид и многих гексактинеллид. Большинство представителей этого семейства париформного строения: очертания парагастральной полости прямо соотносятся с коническим, цилиндрическим или тарелковидным габитусом скелета. Морфологическое разнообразие губок париформного строения обусловлено сочетанием наличия/отсутствия в структуре скелета ризоид, стержня, отворота или изгиба стенки и степенью выраженности их соотношений. Поэтому какие-либо новообразования в строении скелета этих губок с учетом первичной и рецентной сохранности уверенно прослеживаются. По мере накопления фоссильного материала, находок экземпляров с характерными выростами и хорошей сохранности становилось очевидным, что это скелеты обособленной группы губок.

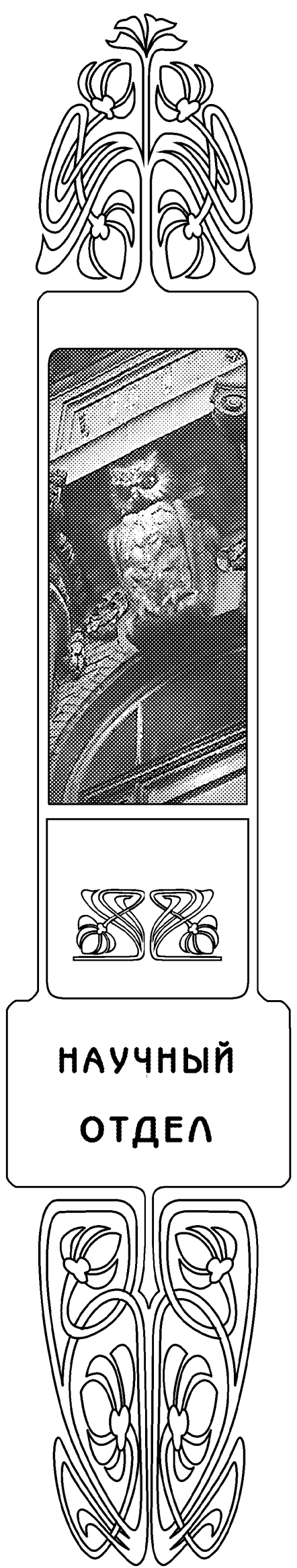


Губки со многими выростами на парагастральной поверхности грибообразного скелета выделены в самостоятельную группу на уровне подрода: Ventriculites (Contubernium). Морфология представителей этой группы отражает одно из направлений в морфогенезе гексактинеллид, проявившееся в сантонский этап их истории. В позднем коньяке - раннем сантоне на юго-востоке Восточноевропейской палеобиогеографической провинции отмечалось широкое площадное расселение многочисленных кремниевых губок, сопровождавшееся формообразованием на уровне вида и подрода/рода.

Формы, на поверхности скелета которых установлены выросты с дополнительными, выводящими отверстиями (оскулюмами, субоскулюмами) и не сообщающимися с центральной парагастральной полостью, определены как перифронтальные [3]. Среди перифронтальных губок выделены две группы, представители которых отличаются расположением почковидных новообразований на парагастральной (Ventriculites (Contubernium)) или дермальной поверхности стенки (Rhizopoterion (Columelloculus)).

Происхождение парагастральных перифронтальных форм. Появление Contubernium связывается с незавершенным парагастральным почкованием представителей Ventriculites (рисунок). Это одиночные губки париформного строения. Скелетообразующая стенка составляет скелет конусовидных очертаний, к ее верхнему краю приурочены зоны активного роста организма, его морфологической изменчивости и почкования [4]. Для вентрикулитид свойственен секторальный или концентрический широкий отворот стенки, в частности в горизонтальной плоскости. В этом случае зоны почкования располагались в наиболее приподнятых секторах парагастральной поверхности стенки (рисунок, фиг. 1, 2). В строении многих гексактинеллид и демоспонгий зоны почкования были приурочены к апикальным участкам тела. Подобная локация образования почек обусловлена тем, что они расположены на наиболее молодых участках организма, от которых с большей вероятностью происходит отделение и перемещение почек в водной среде под влиянием течений [4].

Парагастральная поверхность скелетообразующей стенки обычно полускрыта внутри скелета. При отвороте стенки парагастральная поверхность обращена к внешней среде, что способствует реализации ее предрасположенности к новообразованиям. Именно к секторам широкой горизонтальной парагастральной поверхности стенки приурочено формирование невысоких конических новообразований с короткой цилиндрической полостью и выводящим отверстием. Конические выросты на парагастральной поверхности отворота стенки рассматриваются как проявление унаследованного незавершенного почкования. Появление этих новых элементов спо- собствовало преобразованию очертаний несущего скелета. Конический бокал с прямыми стенками стал низким и узкоконическим, а парагастральная полость - узкой. Оскулюм приобрел округлое очертание небольшого диаметра, его контуры подчеркнуты высокой бровкой, а верхний край расположен в горизонтальной плоскости.

Можно также предположить, что формирование парагастральных перифронтальных форм обусловлено преобразованием поперечных каналов (апохет) в обособленные полости, которые внешне выражены в виде выростов. Подобные выросты наблюдаются даже на дермальной поверхности губок, ирригационная система которых состоит из тонких поперечных каналов с большой плотностью расположения элементов скульптуры. Многочисленные выросты, сформированные по поперечным каналам, установлены в структуре скелетов губок Guettardiscyphia (Hexactinosa), a также известны среди Napaeana (Lychniscosa) [5]. Морфологическое разнообразие перифронтальных форм ограничено и определяется их происхождением от париформных губок - приуроченностью субмодулей к парагастральной или дермальной поверхности скелетообразующей стенки (стержня).

Особенности строения и модульная организация. В структуре модульной организации позднемеловых гексактинеллид перифронтальные представители группы рассматриваются в составе унитарных губок наряду с одиночными и автономными формами [5]. В отличие от предковых, одиночных форм в скелете перифронтальных спонгий выделяется не только центральная парагастральная полость с оскулюмом, но и самостоятельные новообразования с небольшими цилиндрическими полостями и субоскулюмами. Эти элементы единого скелета морфологически обособлены, размеры полостей и диаметр субосулюмов значительно меньше основной полости и оскулюма. Полости новообразований не сопряжены с центральной парагастральной полостью и ирригационной системой несущего организма, на дермальной или парагастральной поверхности которого расположены.

Подобное строение скелета, на наш взгляд, соответствует домодульному уровню организации губок, так как отчетливо выражена структура одиночных губок, осложненная новообразованиями в виде субмодулей, несколько видоизменяющих облик исходного организма [3]. Термин «субмодуль» обозначает подчиненную, вторичную роль дополнительных элементов в строении единого скелета губки. «Субмодули» не являются самостоятельными элементами в строении организма, что хорошо просматривается при сравнении перифронтальных форм со структурой скелетов, образованных многими модулями, равнозначными по габитусу, размерам и функциональному содержанию (автономные формы) [5]. Термин «субоскулюм» больше используется при харак- 


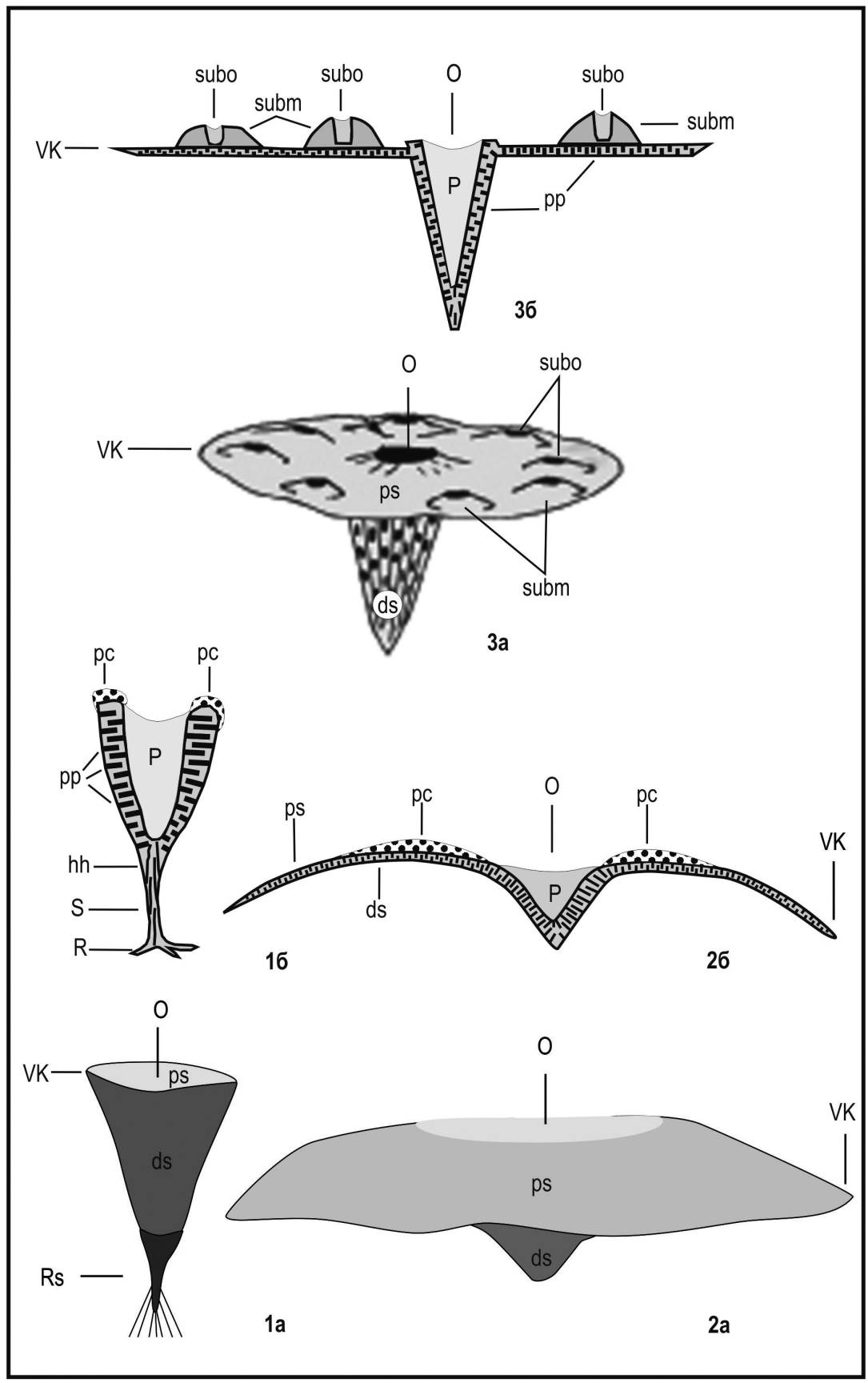

Морфология скелета предковых унитарных форм Ventriculites и производных перифронтальных губок Contubernium

Фиг. 1. Строение унитарных париформных губок без отворота стенки (Ventriculites striatus T. Smith, 1848): 1a - общий вид; 16 - продольное, вертикальное сечение скелета. Верхний мел Европы. Фиг. 2. Строение унитарных париформных губок с широким равносторонним и выпуклым отворотом стенки (Ventriculites cribrosus (Phillips, 1829)): 2а - общий вид; 26 - продольное, вертикальное сечение скелета. Турон - сантон Европы. Фиг. 3. Строение перифронтальных губок, у которых субмодули расположены на парагастральной поверхности несущей стенки (Ventriculites (Contubernium) ochevi Pervushov, 1998): 3а - общий вид; 36 - продольное, вертикальное сечение скелета через оскулюм и субмодули. Нижний сантон правобережного Поволжья, Россия. Условные обозначения: $\mathrm{O}$ - оскулюм, $\mathrm{P}$ - парагастральная полость, $\mathrm{R}$ - ризоиды, Rs - ризоидный вырост, $\mathrm{S}$ - стержень, VK - верхний край, subm - субмодуль, subo - субоскулюм, pc - зоны активного почкообразования; элементы ирригационной системы: hh - продольные каналы и $\mathrm{pp}$ - поперечные каналы, ds - дермальная (темно-серый фон) и ps - парагастральная (светло-серый фон) поверхности стенки 
теристике транситорных форм (Coeloptychium, Balantionella, Guettardiscyphia и Tremabolites), отражая вторичную, дополнительную роль этих мелких по сравнению с оскулюмом отверстий в скелете губки с единой парагастральной полостью.

Аспекты номенклатуры и систематики. Перифронтальные формы рассматриваются на уровне подрода, в составе рода, с представителями которого предполагается их филогенетическая обусловленность. Среди вентрикулитид важными таксономическими признаками на уровне рода являются характеристика дермальной скульптуры и ее соотношение со скульптурой парагастральной поверхности стенки [2]. Субмодули с обособленными полостями дополняют и несколько видоизменяют очертания скелета исходных родственных форм, но строение дермальной скульптуры и ирригационной системы остается идентичным. Поэтому представители перифронтальных Contubernium рассматриваются в составе Ventriculites. Относительно короткое время существовавшие монотипные группы, подобные Contubernium, представляли конечные, специализированные тренды морфогенеза в ранге трибы (подсемейства) [1, 2].

\section{Описание}

Тип Hexactinellida

Подотряд Lychniscosa A. Schrammen, 1903

Семейство Ventriculitidae J. Phillips, 1829-1836

Д и а г н о з. Бокал париформный, его строение в разной степени дополняют стержень и/или ризоиды. Скелетообразующая стенка с поперечными каналами, их устья являются негативными элементами дермальной и парагастральной скульптур. Характерен унитарный уровень организации, известны одиночные и перифронтальные формы, а также полиоскулюмные губки автономного строения.

С о с т а в . Два подсемейства: Ventriculitinae J. Phillips, 1829-1836; Rhizopoterioninae A. Goldfuss, 1833.

Р а с п р о с т р а н е и е. Верхний мел-палеоген, ? ныне.

\section{Подсемейство Ventriculitinae J. Phillips, 1829-1836}

Д и а г о з. В основании бокаловидного скелета развиты ризоиды или на дермальной поверхности стенки присутствуют шиповидные основания пучков ризоидных спикул. Скелетообразующая стенка пронизана слепыми поперечными цилиндрическими апо- и прозохетами с пилами, контуры каналов очерчены каналярной спикульной решеткой. Проксимальные продольные каналы плотно расположены в ризоидах. Интерканалярная спикульная решетка образована призматическими и кубическими клетями размером 0,25-0,38-0,5/0,25-0,38-0,5 мм. Кортекс присутствует на всех поверхностях стенки. В основании парагастральной полости сохраняется пористая паренхимальная спикульная решетка с меандрирующими в вертикальной плоскости каналами.

С о с т а в . Две трибы: Ventriculitini J. Phillips, 1829-1836; Microblastini I. Sinzov, 1872.

Сравнение. От Rhizopoterioninae отличается отсутствием стержня с гладкими проксимальными каналами без каналярной спикульной решетки.

Р а с п р о с т р н е н и е. Альб, верхний мел - палеоген Европы, Северной Африки, юг Урала и Западной Сибири.

\section{Триба Ventriculitini J. Phillips, 1829-1836}

Д и а г н о 3 . Толстостенные париформные бокалы с минимальной плотностью расположения элементов дермальной скульптуры.

C о с т а в . Подтриба Ventriculitina J. Phillips, 1829-1836.

Сравнение. От Microblastini отличается продольно-линейной ориентацией элементов дермальной скульптуры с выдержанными очертаниями и размером прозопор.

\section{Подтриба Ventriculitina J. Phillips, 1829-1836}

Д и а г н о 3 . Дермальная скульптура образована продольными параллельными ребрами и бороздами, дихотомирующими на участках изгиба и пережима стенки. В бороздах расположены округлые прозопоры и прямоугольные узлы ребер. На гладкой парагастральной поверхности регулярно расположены овальные остия. Соотношение скульптур поверхностей стенки реактивное.

С о с т а в . Пять родов: Ventriculites (J. Phillips, 1829-1836); Cephalites (T. Smith, 1848); Pleuropyge A. Schrammen, 1912; Rhizopoterionopsis J. Lachasse, 1943; Divicalys Pervushov, 1998.

Род Ventriculites (J. Phillips, 1829-1836)

Spongia cribrosa: J. Phillips, 1829-1836, табл. 1, фиг. 7; Geinitz, 1842, с. 95.

Т и п о в о й в и д - Spongia cribrosa J. Phillips, 1829-1836; верхний мел, Англия.

Д и а г н 3 . Габитус и параметры бокала определяются степенью развития отворота: обычно чем большую площадь он занимает, тем меньше высота нижней - конической - части. Толщина стенки сантонских форм 6-10 мм, реже до 12-14 мм, кампанских - 2-6 мм, уменьшается к верхнему краю. В основании бокала присутствует площадка прикрепления или короткий ризоид. Позитивные элементы дермальной скульптуры представлены широкими ребрами (1,5-2 мм) и низкими прямоугольными узлами ребер (0,5-2/3-5 мм). Прозопоры овально-вытянутые (1,5-2/3-4 мм). На $1 \mathrm{~cm}^{2}$ дермальной поверхности приходится 3-5 ребер, 2-4 борозды и 5-7 прозопор. 
Замечан ия . Исследователи очень широко трактуют содержание этой таксономической группы, рассматривая в ее составе представителей родственных групп (Sporadoscinia, Sororistirps и изоморфных представителей Hexatinosa). B данном случае, в качестве типового вида принято наиболее раннее описание представителя рода, морфологическая характеристика которого однозначно соответствует содержанию таксона.

Сравнение. От Cephalites отличается меньшей толщиной стенки и высоким бокалом с большей плотностью расположения элементов дермальной скульптуры, широким отворотом стенки.

C о с т а в. Два подрода: Ventriculites (Ventriculites) (J. Phillips, 1829-1836), Ventriculites (Contubernium) Pervushov, 1998.

Р а с п р остранен ие. Мел (апт- маастрихт) и палеоцен Европы.

\section{Подрод Contubernium Pervushov, 1998}

Contubernium Pervushov: Первушов, 1998, c. 111.

Ventriculites (Contubernium) Pervushov: Пepвушов, 2019, с. 54.

Наз ван и е подрода от contubernium лат. общежитие.

Ти по во й в ид - Contubernium ochevi Pervushov, 1998; верхний мел, нижний сантон Поволжья (европейская часть России).

Ди аг н о 3. Губки унитарного уровня модульной организации и перифронтального строения, с расположением субмодулей на парагастральной поверхности стенки. Бокал конический с широким ортогональным отворотом стенки в горизонтальной плоскости. Диаметр отворота в 1,5-2 раза превышает высоту бокала. Центральный парагастр глубокий и субцилиндрический. Оскулюм округлый, диаметром 8-10/11-12 мм. Толщина стенки изменяется от 6-8 мм до 10-11 мм. Дермальные ребра и борозды шириной 1-2 мм, у крупных форм ребра неотчетливы. Узлы ребер узкие: 0,5/3-5 мм. Прозопоры овально-вытянутые - 1-2/2-4 мм. На парагастральной поверхности стенки, обращенной к верху при ее отвороте в горизонтальную плоскость, расположены канавки каналов ( $1-1,3$ мм) и их тонкие стенки $(0,5-0,6$ мм), а также овально-вытянутые остия. Апо- и прозохеты диаметром 1,5-2 мм, порой диагональные в области бокала, расширяются к устью. У крупных форм отмечаются небольшие пилы. На горизонтальном участке парагастральной поверхности стенки распространены слабо выпуклые бугорки (субмодули) с круглыми субоскулюмами и мелкой цилиндрической полостью, количество которых возрастает с увеличением площади отворота. Интерканалярные кубические клети размером $0,25-0,5$ мм, диаметр спикул $0,04-0,06$ мм, узла лихнисков $0,1-0,14$ мм. На 1 см$^{2}$ дермальной поверхности приходится 3-4 ребра, 3 борозды и 3-5 прозопор.
Замеч ан и я. Изучение в аншлифах (фототабл. 3, фиг. 1a) соотношения парагастральной полости и ирригационной системы несущего скелета и полостей субмодулей позволило предположить обособленное функционирование систем жизнеобеспечения несущего организма и дочерних новообразований.

Видов ой состав. Типовой вид.

Сравнение. Среди унитарных вентрикулитид выделяется перифронтальным подуровнем организации - наличием субмодулей на парагастральной поверхности отворота стенки.

Р асп постранение. Нижний сантон правобережья Саратовской и Волгоградской областей.

\section{Ventriculites (Contubernium) ochevi Pervushov, 1998}

Табл. 1, 2, 3; Табл. 4, фиг. $2,3$.

Contubernium ochevi-Первушов, 1998, с. 111, табл. 14 , фиг. 2 .

Н а з ван и е вид а в честь палеонтолога В. Г. Очева.

Го л о т и п - PEM, № 121/1278; г. Саратов, нижний сантон.

П а р а т и п - PEM, № 121/28; г. Саратов, карьер завода силикатного кирпича, нижний сантон.

О п и с а н и е. Высота скелета 30-40 мм, диаметр по верхнему краю 60-70 мм. Оскулюм овальный (8-10/11-12 мм), острые края окружающей его стенки в виде кратера приподняты над парагастральной поверхностью. Конусообразный бокал невысокий - 19-31 мм, его диаметр до отворота 22-30 мм, стенка выпуклая. Над бокалом развит широкий равномерный ортогональный отворот в горизонтальной плоскости. После отворота нижняя поверхность стенки плоская и слабоволнистая. На верхней, парагастральной, поверхности стенки по окружности расположены небольшие конусовидные субмодули с мелкими субоскулюмами (3-6/3-6 мм) в центре. Количество субмодулей у форм полной сохранности при диаметре отворота до 50-60 мм изменяется от 7 до 12. Субмодули расположены равномерно концентрически по всей парагастральной поверхности. На поверхности субмодулей прослеживаются элементы скульптуры. Крупные формы известны по фрагментам горизонтальной стенки (фототабл. 2).

Он тогене 3. Строение скелетов взрослых и зрелых форм известно по крупным фрагментам отворота (фототабл. 2, фиг. 1б-в; фототабл. 4, фиг. 2, 3б). В индивидуальном развитии губок отмечено проявление нескольких сопряженных тенденций в преобразовании элементов скелета. Наиболее заметно возрастание площади горизонтального отворота стенки, что сопровождалось увеличением количества субоскулюмов от 15-20 до 50-60. Но при этом многочисленные субмодули утрачивали отчетливо выраженные конические очертания, на их месте прослеживаются лишь субоскулярные отверстия, которые становились более крупны- 
ми и овальными. Увеличение площади отворота стенки, дискообразной части скелета особенно заметно при сравнении с его нижней, конической, частью, высота которой оставалась неизменной на протяжении большей части жизни организма.

Формирование концентрического широкого отворота стенки сопровождалось появлением на нижней ее поверхности выростов, выполнявших функции ризоидов - подпорок. В строении форм с небольшим отворотом эти выросты представляют собой узкие асимметричные конусовидные образования, опущенные вниз от участков дермальных ребер. У более крупных форм эти выросты сливались воедино, образуя протяженные радиальные узкие валики, высота которых увеличивалась по направлению к верхнему краю до 20-25 мм. Последующее развитие выростов в связи с усилением их опорных функций приводило к искажению очертаний скелета зрелых губок. Эти изменения выражались в том, что ровная горизонтальная поверхность стенки, составляющей отворот, становилась плицирующей и неровной. Подобные видоизменения обусловлены тем, что к участкам развития дермальных опорных ризоид на парагастральной поверхности приурочено формирование протяженных желобов, разделенных валиками (фототабл. 4, фиг. 2). Предполагается, что радиально ориентированные опорные выросты поддерживали широкий горизонтально ориентированный сектор стенки над поверхностью дна.

Из о м орфи з м. Среди фоссилий, по внешним признакам отнесенных к роду Contubernium, выделены формы, которые выделяются едва уловимыми внешними морфологическими особенностями. Основанием для рассмотрения выделенных скелетов губок в составе одной таксономической группы было сходное строение верхней горизонтальной поверхности, на которой распространены округлые субоскулюмы или оскулюмы. Изучение строения спикульной решетки позволило отнести часть экземпляров к Ventriculites (Contubernium), подотряд (Lychniscosa), а некоторые фоссилии оказались представителями подотряда Hехаctinosa. При последующем рассмотрении скелетов губок Hexactinosa отмечены внешние признаки, все же отличающие их от Contubernium. Это отсутствие центрального оскулюма в структуре массивного скелета и дермальной скульптуры, наличие концентрических пережимов (фототабл. 4, фиг. 1 ; фототабл. 5). Особенности строения скелета рассматриваемых Hexactinosa позволяют предположить, что в этой группе объединены представители разных таксономических групп. Ареал немногочисленных гексактинос (7 экз.) преимущественно совпадает с участками находок Contubernium.

Фрагменты скелета губок Tremabolites (подотряд Lychniscosa) также внешне напоминают строение парагастральной поверхности Contubernium благодаря наличию многочисленных округлых оскулюмов. В строении скелета некоторых демоспонгий (Actinosiphonia) также прослеживается концентрическое расположение нескольких модулей [5].

Таф он о м я. Значительная часть скелетов губок из верхнемеловых отложений Поволжья происходит из аллохтонных комплексов. В этом случае они часто в той или иной степени фосфатизированы. Тела и скелеты губок даже при автохтонном и субавтохтонном захоронении сорбировали фосфатные соединения из водной среды. Именно эта первичная фоссилизация способствовала порой их идеальной первичной сохранности. Все скелеты Contubernium сильно фосфатизированы, большая их часть либо фрагментирована, либо представлена фрагментами отворота стенки. Это обусловлено тем, что условия обитания Contubernium не совпадали с последующим более активным придонным гидродинамическим режимом, из-за чего тело организма срывалось с места прикрепления либо его скелет вымывался уже из осадка. К тому же габитус этих губок способствовал изменению прижизненного положения скелета после гибели организма: его массивная верхняя дисковидная часть перевешивала нижний конусообразный бокал и переворачивалась на бок. Воздействие придонных течений и волновой динамики воды приводило к волчкообразному вращению скелета. Формы с большим диаметром отворота в подобных условиях раскалывались на сегменты с отделением нижней конусообразной части. При значительной выборке фоссилий лишь единичные формы небольшого диаметра отличаются почти полной сохранностью (фототабл. 1, 3). Селективная сохранность не позволяет представить видовое разнообразие представителей Contubernium: из 31 экземпляра фоссилий известно всего 10\% скелетов полной сохранности. Значительная часть диагностируемых экземпляров Contubernium - это сегменты отворота стенки с субмодулями (фототабл. 2, фототабл. 4, фиг. 2, 3).

Пале о экология. Contubernium были распространены в составе губково-моллюсковых сообществ на зрелых этапах сукцессии, которая развивалась с позднеконьякского по раннесантонское время. Они образовывали локальные поселения в интервале средней сублиторали. Губки Contubernium можно рассматривать как эндемичные формы в составе раннесантонского спонгиосообщества.

Р аспространение. Нижний сантон правобережья Саратовской и Волгоградской областей, большая часть местонахождений приурочены к юго-восточной части Саратовских дислокаций.

Матери ал. 31 экз., аншлифы.

Местон ахожден и я. Саратовская область: «Александровка-1», «Багаевка», «Карамышка», «Красный Текстильщик», «Мезино-Лапшиновка-2», «Озерки-1-4», «Пудовкино-1», «Репная 
Фототаблииа 1

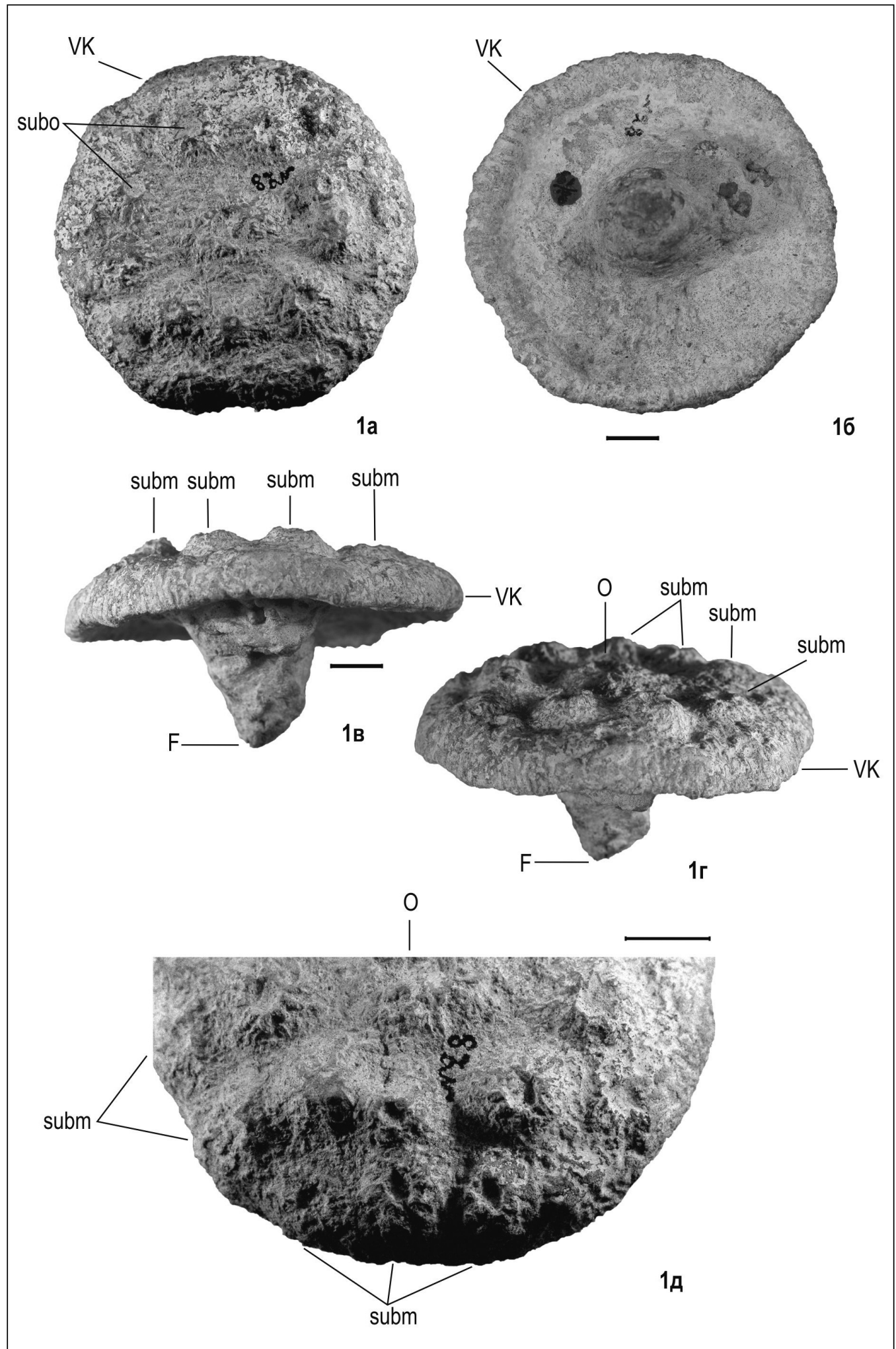

Фототаблица 1

Фиг. 1. Ventriculites (Contubernium) ochevi Pervushov, 1998. Экз. РЕМ, № 121/28: скелет полной сохранности: 1а - сверху, 16 - снизу, 1в - сбоку, 1г - по диагонали сверху, 1д - половина верхней части скелета с оскулюмом в центре и два концентрических ряда субмодулей; г. Саратов. Сантон. Условные обозначения: О - оскулюм, VK - верхний край, F - основание скелета, subm - субмодуль, subo - cyбоскулюм. Длина масштабной линейки 10 мм. 
Фототаблица 2

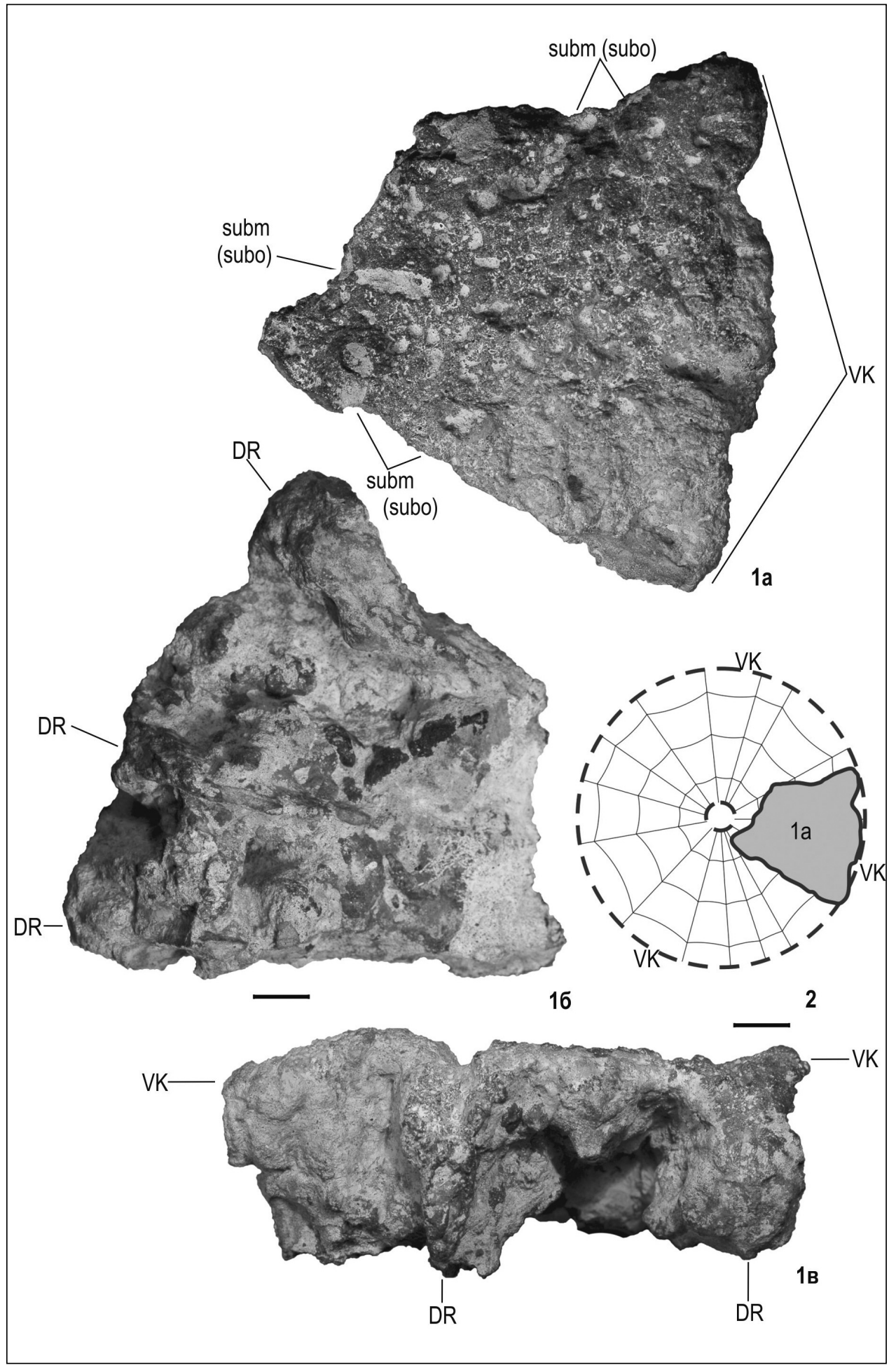

Фототаблица 2

Фиг. 1. Ventriculites (Contubernium) sp. ind. Экз. РЕМ, № 121/2442: фрагмент сектора горизонтального отворота: 1а - сверху, оскулярные отверстия субмодулей, 16 - снизу, радиальные протяженные ризоидные выросты, 1в - сбоку, верхний край с ризоидными выростами; г. Саратов, местонахождение «Заплатиновка». Нижний сантон. Фиг. 2. Ventriculites (Contubernium) sp. ind. Экз. РЕМ, № 121/2442: реконструкция скелета и положение представленного на фиг. 1 его фрагмента (серое), вид сверху; г. Саратов, местонахождение «Заплатиновка». Нижний сантон. Условные обозначения: DR - дополнительные ризоидные выросты, VK - верхний край, subm (subo) - субмодуль (субоскулюм). Длина масштабной линейки 10 мм. 
Фототаблица 3

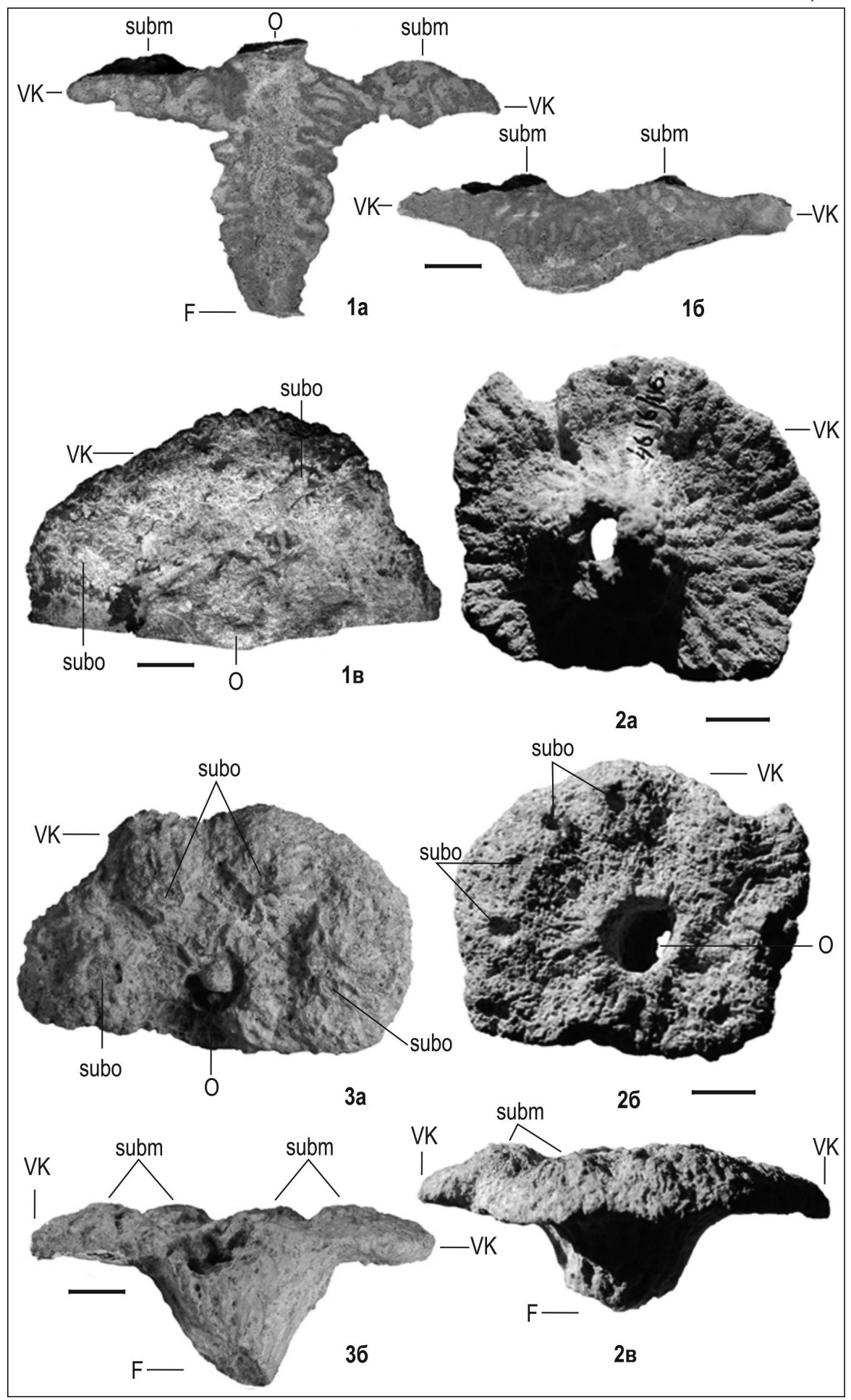

Фототаблица 3

Фиг. 1. Ventriculites (Contubernium) ochevi Pervushov, 1998. Экз. РЕМ, № 122/1278: скелет без вмещающей породы: $1 \mathrm{a}$-продольный аншлиф, стенка бокала с поперечными каналами, 16 - аншлиф стенки выше отворота, 1в - сегмент отворота стенки сверху; г. Саратов. Нижний сантон. Фиг. 2. Ventriculites (Contubernium) ochevi Pervushov, 1998. Экз. PEM, № 121/1951: 2a - снизу, 2б - сверху, 2в - сбоку; г. Саратов, местонахождение «Заплатиновка». Нижний сантон. Фиг. 3. Ventriculites (Contubernium) ochevi Pervushov, 1998. Экз. РЕМ, № 121/1885: $3 \mathrm{a}$ - сверху, $3 б$ - сбоку; Саратовская область, местонахождение «Карамышка». Нижний сантон. Условные обозначения: О - оскулюм, VK - верхний край, $\mathrm{F}$ - основание скелета, subm - субмодуль, subo - субоскулюм. Длина масштабной линейки 10 мм. 


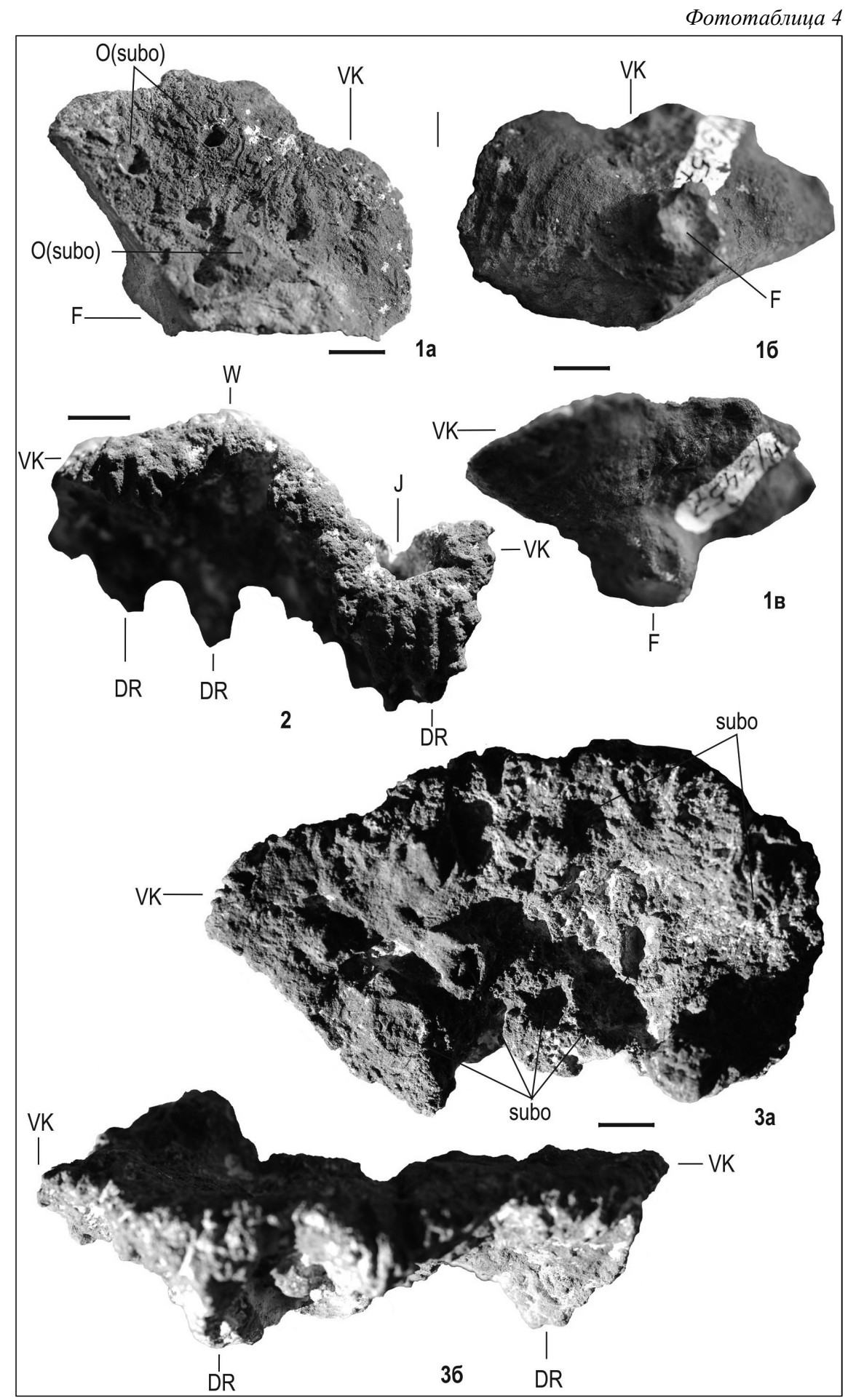

Фототаблица 4

Фиг. 1. Hexactinosa insertae sedis. Экз. РЕМ, № 122/3457: фрагментированный скелет: 1а - сверху, 1б - сбоку, 1в - снизу; Саратовская область, местонахождение «Озерки-1». Нижний сантон. Фиг. 2. Ventriculites (Contubernium) sp. ind. Экз. РЕM, № 122/4942: фрагмент скелета, сегмент горизонтального отворота стенки сбоку, вид на верхний край; Саратовская область, местонахождение «Озерки-3». Нижний сантон. Фиг. 3. Ventriculites (Contubernium) sp. ind. Экз. РЕM, № 122/5979: сегмент горизонтального отворота стенки: 3а - сверху, $3 б$ - сбоку, вид на верхний край; Саратовская область, местонахождение «Карамышка». Нижний сантон. Условные обозначения: DR - дополнительные ризоидные выросты, J - желоба, O (subo) - оскулюм (субоскулюм), VK - верхний край, F - основание скелета, W - валики, subo - субмодуль. Длина масштабной линейки 10 мм. 
Фототаблииа 5

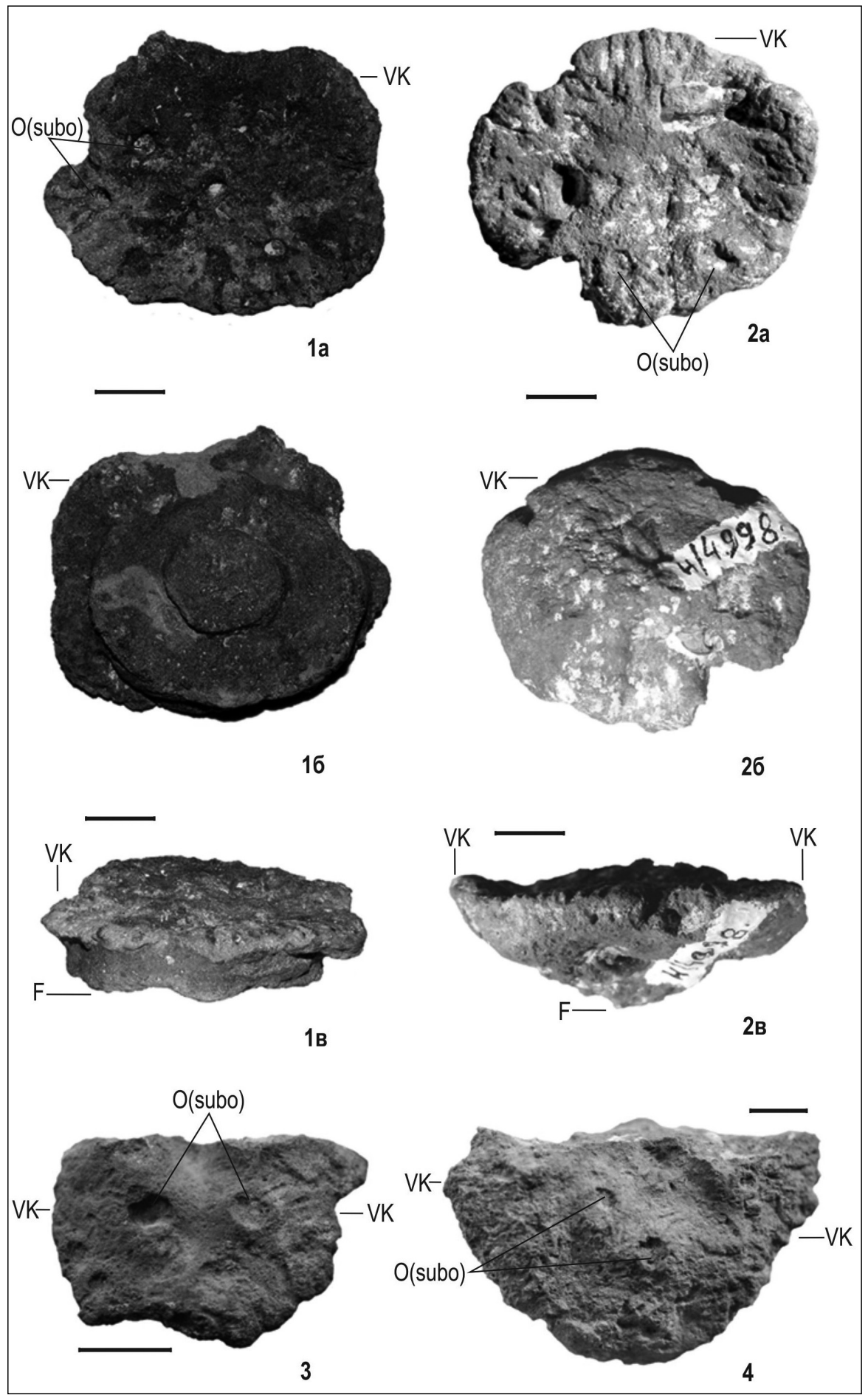

Фототаблица 5

Фиг. 1. Hexactinosa insertae sedis. Экз. РЕМ, № 122/5999: скелет полной сохранности с пережимами: 1а - сверху, 1 - снизу; 1в - сбоку; Саратовская область, местонахождение «Озерки-3». Нижний сантон. Фиг. 2. Hexactinosa insertae sedis. Экз. PEM, № 122/4998: $2 \mathrm{a}$ - сверху, 2б - снизу, 2в - сбоку; Саратовская область, местонахождение «Озерки-2». Нижний сантон. Фиг. 3. Hexactinosa insertae sedis. Экз. РEM, № 122/5759: фрагмент скелета, вид сверху; Саратовская область, местонахождение «Озерки-2». Нижний сантон. Фиг. 4. Hexactinosa insertae sedis. Экз. РЕM, № 122/7521: фрагмент скелета, вид сверху; Саратовская область, местонахождение «Озерки-4». Нижний сантон. Условные обозначения: O (subo) - оскулюм (субоскулюм), VK - верхний край, F - основание скелета. Длина масштабной линейки 10 мм. 
Вершина»; г. Саратов: Лысая гора, «Заплатиновка», «Карьер завода силикатного кирпича»; Волгоградская область: «Мирошники».

\section{Библиографический список}

1. Первушов Е. М. Позднемеловые вентрикулитидные губки Поволжья // Труды / НИИ геологии Саратовского университета. 1998. Т. 2. 168 с.

2. Первушов E. М. Состав и структура семейства Ventriculitidae (Porifera, Hexactinellida) // Изв. Сарат. ун-та. Нов. сер. Сер. Науки о Земле. 2019. Т. 19, вып. 1.
C. 49-62. DOI: https://doi.org/10.18500/1819-7663-201919-1-49-62

3. Первушов Е. М. Перифронтальные формы модульных гексактинеллид // Изв. Сарат. ун-та. Нов. сер. Сер. Науки о Земле. 2012. Т. 12, вып. 1. С. 56-66.

4. Первушов Е. М. Проявления почкования среди позднемеловых скелетных губок - гексактинеллид // Изв. Сарат. ун-та. Нов. сер. Сер. Науки о Земле. 2010. Т. 10, вып. 1. С. 51-64. 5. Первушов E. М. Морфотипы и модульная организация позднемеловых гексактинеллид (Porifera, Hexactinellida). Саратов : Издательство Саратовского университета, 2018. $208 \mathrm{c}$.

\section{Образец для цитирования:}

Первушов Е. М. Contubernium Ochevi (Porifera, Hexactinellida) // Изв. Сарат. ун-та. Нов. сер. Сер. Науки о Земле. 2019. T. 19, вып. 4. C. 267-278. DOI: https://doi.org/10.18500/1819-7663-2019-19-4-267-278

\section{Cite this article as:}

Pervushov E. M. Contubernium Ochevi (Porifera, Hexactinellida). Izv. Saratov Univ. (N. S.), Ser. Earth Sciences, 2019, vol. 19, iss. 4, pp. 267-278 (in Russian). DOI: https://doi.org/10.18500/1819-7663-2019-19-4-267-278 